\title{
GALLOP SOUNDS IN HYPERTENSION AND MYOCARDIAL ISCHÆMIA MODIFIED BY RESPIRATION AND OTHER MANEUVRES
}

\author{
BY \\ ELDRYD PARRY AND PATRICK MOUNSEY \\ From the Department of Medicine, Postgraduate Medical School, of London \\ Received January 20, 1961
}

The term "gallop sounds" was first introduced by Bouillaud in 1847 (Potain, 1900) to describe the cadence of heart sounds where a succession of three sounds is heard instead of the normal two. The significance of gallop sounds was emphasized by Potain, Bouillaud's pupil, and his description of the probable mode of production of both presystolic gallop from the addition of an atrial sound, and proto-diastolic gallop from a third heart sound, is so clear that it will be quoted in full. $\mathrm{He}$ describes the association of an atrial gallop with Bright's disease and says (Potain, 1880):

"Normally after the ventricle has emptied, it then dilates, filling with blood brought partly by the vis a tergo and partly by atrial contraction, which completes ventricular filling. The atrium, therefore, normally plays only an accessory role. But, when the ventricle is little distended, the action of the atrium becomes of greater importance, for, if little blood arrives from the venous side, little arrives in the ventricle, and so the atrium is obliged to complete filling of the ventricle-hence the more active role of the atrium and the sudden lift during its contraction, which is presumably our gallop sound. It is not exclusively a pathological phenomenon: it is rather an exaggeration of a normal phenomenon."

Of protodiastolic gallop, due to a third heart sound, he says (Potain, 1900):

"If the cardiac muscle loses its tonicity, the ventricle in dilating arrives rapidly at the point where resistance of the fibres of its wall limits its distension; then, suddenly arrested, it produces a tension, shock, and gallop sound."

Potain thought of gallop sounds as essentially ventricular filling sounds. Although others have suggested that premature closure of the atrio-ventricular valves may sometimes contribute to the genesis of the third sound (Gibson, 1907; Thayer, 1908), Potain's theory of ventricular filling as the underlying mechanism producing both types of gallop is generally accepted today (McKusick, 1958).

Protodiastolic gallop from accentuation of a third heart sound is a sign of heart failure in older patients (Evans, 1943), indicating a raised venous filling pressure. Presystolic gallop, on the other hand, from accentuation of an atrial sound may persist for many years in patients with few symptoms from their heart disease (Weitzman, 1955; Harvey and Corrado, 1956). Detailed phonocardiographic studies have shown that the precise timing of an atrial sound varies with the clinical state of the patient, an atrial sound at first distinct and separate from the first sound later approaching it or fusing with it, as the patient improved (Duchosal, 1932; Kincaid-Smith and Barlow, 1959).

We have been impressed with the extreme lability and the constantly changing character of the atrial sound and third sound in patients with hypertension and ischæmic heart disease. We, therefore, investigated the effect of certain simple physiological manœuvres, including respiration, postural changes, and light exercise to see how far these factors, in addition to the clinical state of the patient, modified the gallop sounds. 


\section{THE INVESTIGATION DESCRIBED}

In order to follow acute variations of gallop sounds in hypertensive and ischæmic heart disease, a small number of patients were selected for a more prolonged study in the phonocardiogram, each examination lasting two to three hours. Twenty-five patients were selected, of whom 18 had hypertension and 7 ischæmic heart disease. The hypertensive patients were all sufficiently ill to require hypotensive drug therapy and were studied while in hospital for control of treatment. Four of those with ischæmic heart disease were studied during an episode of cardiac infarction, while in three an associated anæmia aggravated their angina. Three of the 25 patients had both hypertension and ischæmic heart disease. All the patients had an atrial sound and three had a third heart sound also.

During the examination the effect of certain simple physiological manœuvres was tested, namely normal respiration, halted respiration, sitting up and lying down, and in some patients gentle exercise. In addition two further methods were used to vary gallop sounds, venous pooling by cuffing the legs and the intravenous injection of aminophylline.

In order to obtain basal conditions at the beginning of the examination, the patient was allowed to rest quietly in the phonocardiograph room for about 15 minutes, before the first phonocardiogram was recorded. The sounds were recorded in the mitral area, using a low frequency filter. A simultaneous electrocardiogram and phonocardiogram from another area were used as reference tracings and in some cases a carotid pulse tracing and an apex cardiogram were also recorded. The blood pressure was taken with each sound record throughout the study. Any outside noise or interruption likely to disturb basal conditions was avoided.

The effect of respiration on the gallop sounds was studied in 8 patients. A phonocardiogram was first recorded during normal quiet respiration. The patient then took a deep breath in and held it for about six heart beats, during which time a continuous phonocardiogram was recorded. A similar record was taken immediately on completion of expiration, the patient once again holding his breath for about six heart beats.

Change of posture from the sitting to lying position was studied in 18 patients. The patient was sat up for 10 minutes in a cardiac bed with the feet down and a phonocardiogram was recorded. He was then laid flat, the adjustable portions of the cardiac bed being brought to the horizontal, and a second record was taken immediately. All phonocardiograms in this and subsequent studieswere recorded at the end of full expiration and continued for about six heart beats.

The effect of exercise was studied in 11 patients. Exercise was performed by gentle bicycling movements of the legs against light manual pressure with the patient lying flat in bed, until he began to be breathless. A phonocardiogram was recorded immediately after exercise and serial records taken until breathlessness had passed.

Venous pooling, by the application of inflated cuffs to the thighs, was studied in 9 patients. Its effect on the gallop sounds was examined both with the patient sitting up and lying down. The following routine was repeated in each case. A phonocardiogram was first recorded with the patient sitting up. Cuffs were then applied to both thighs at a pressure of about $80 \mathrm{~mm} . \mathrm{Hg}$ and serial phonocardiograms recorded for up to 40 minutes, with the patient still sitting up. He was then laid flat with the cuffs in position and further phonocardiograms were recorded for about 10 minutes. Finally the cuffs were released and more records were taken with the patient still lying flat for about 15 minutes.

In 7 patients the effect of intravenous injection of $0.5 \mathrm{~g}$. aminophylline was investigated. The injection was given slowly over a period of 3 minutes. Phonocardiograms were recorded immediately, and afterwards at regular intervals for up to 40 minutes.

Definition of an Atrial Sound. The interval between the beginning of the $Q$ wave in the electrocardiogram and the first heart sound sometimes contains low frequency vibrations, due at least in part to atrial systole and therefore constituting an atrial sound (Kincaid-Smith and Barlow, 1959). Harrison (1959), however, has shown that in ultra-low frequency tracings from the præcordium a succession of small vibrations occur after the $Q$ wave and before closure of the atrio-ventricular 
valves in normal subjects and that, while some are due to atrial contraction, others are probably ventricular in origin. One should hesitate, therefore, to ascribe vibrations during this period to atrial systole, without special additional evidence, such as variation in the sound with alteration in the length of the P-R interval. In this study we accepted, as evidence of an atrial sound, vibrations following the $P$ wave that preceded or lay around the $Q$ wave in the electrocardiogram. Vibrations clearly following the $Q$ wave were only accepted as an atrial sound in one hypertensive patient, in whom they were of unusually large amplitude. No more accurate timing of the atrial sound than a broad relationship to the $\mathrm{Q}$ wave was attempted, since it was felt that the width of the sound in the phonocardiogram and its often ill-defined beginning made more detailed estimation of the exact interval between the $\mathbf{P}$ wave and the atrial sound impracticable in our group of patients. No attempt was made to divide the sound into two components, the audible and the inaudible, as described by Weitzman (1955). It was recognized, however, that the atrial sound was merely the terminal portion of a complex of small vibrations in a low-frequency phonocardiogram, extending throughout atrioventricular filling as indicated in a simultaneous apex cardiogram (Fig. 1), of which only the later vibrations were sufficiently large or of high enough frequency to be audible.

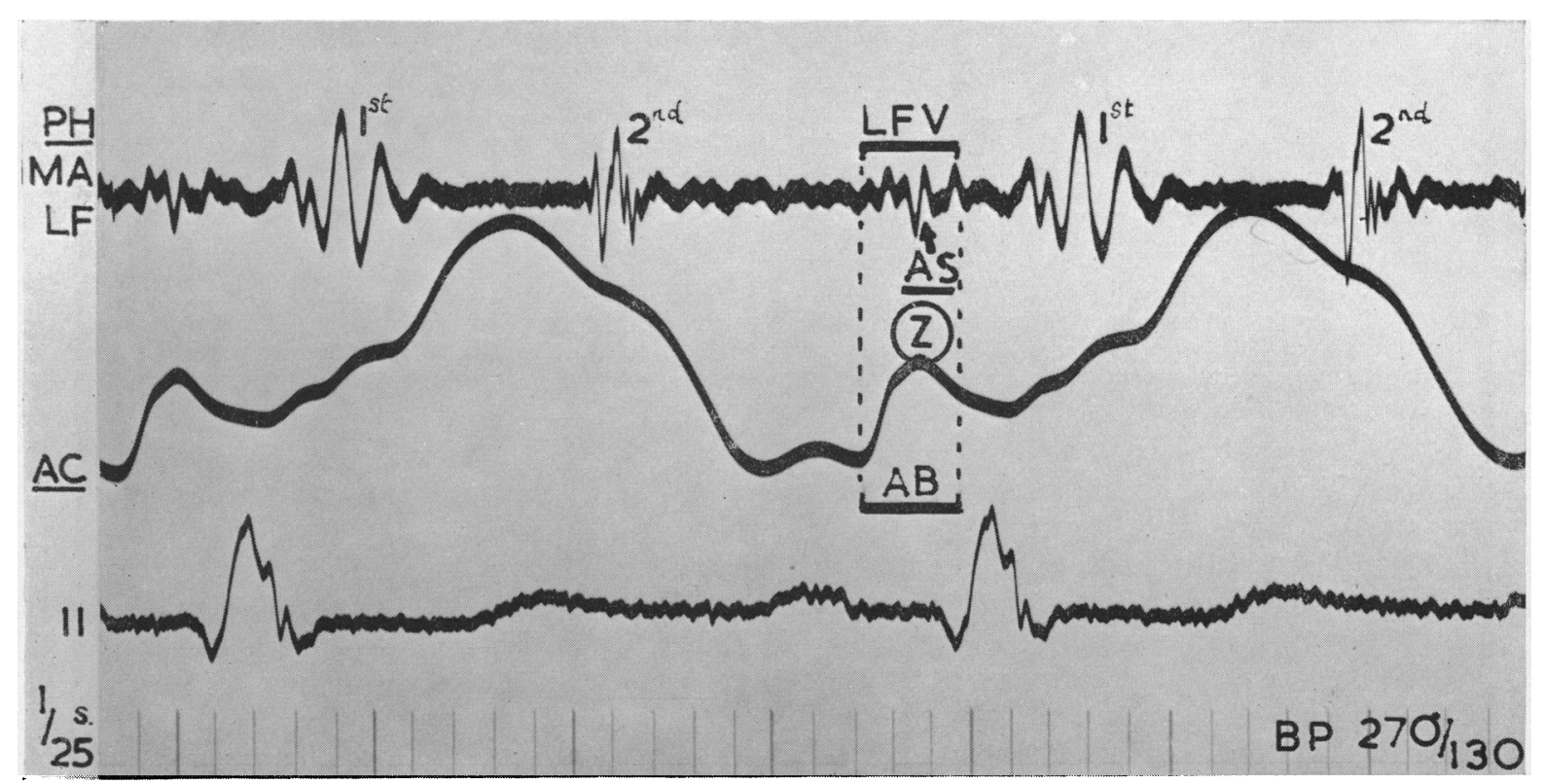

FIG. 1.-Hypertensive heart disease with atrial gallop. Relationship of atrial sound to præcordial pulsation. Lowfrequency vibrations (LFV) in phonocardiogram (PH) in mitral area (MA) continue throughout atrial beat (AB) recorded in apex cardiogram (AC). Only larger and higher frequency vibrations clearly audible as atrial sound (AS), occurring at zenith (Z) of outward atrial beat. Apex cardiogram recorded with photo-electric cell, Electrocardiogram lead II. 1 st and 2 nd = first and second heart sounds.

\section{RESULTS}

The Atrial Sound. The Effect of Respiration. During normal quiet respiration phasic variation in amplitude of the atrial sound was seen in all 8 patients studied, the sound being loudest at the beginning of expiration. A minor transient increase at the beginning of inspiration was also seen in 2 of these 8 patients, both of whom were in congestive heart failure.

Halting of respiration, either in full expiration or full inspiration, profoundly modified the phonocardiogram in 4 of the 8 patients: 3 of these had hypertension and 1 ischæmic heart disease, so that the behaviour of the sound was not peculiar to either disease. A record taken in held expiration, starting immediately at the end of expiration and continued for 5 to 6 heart beats, showed gradual diminution in amplitude of the atrial sound with final disappearance (Fig. 2). Changes 


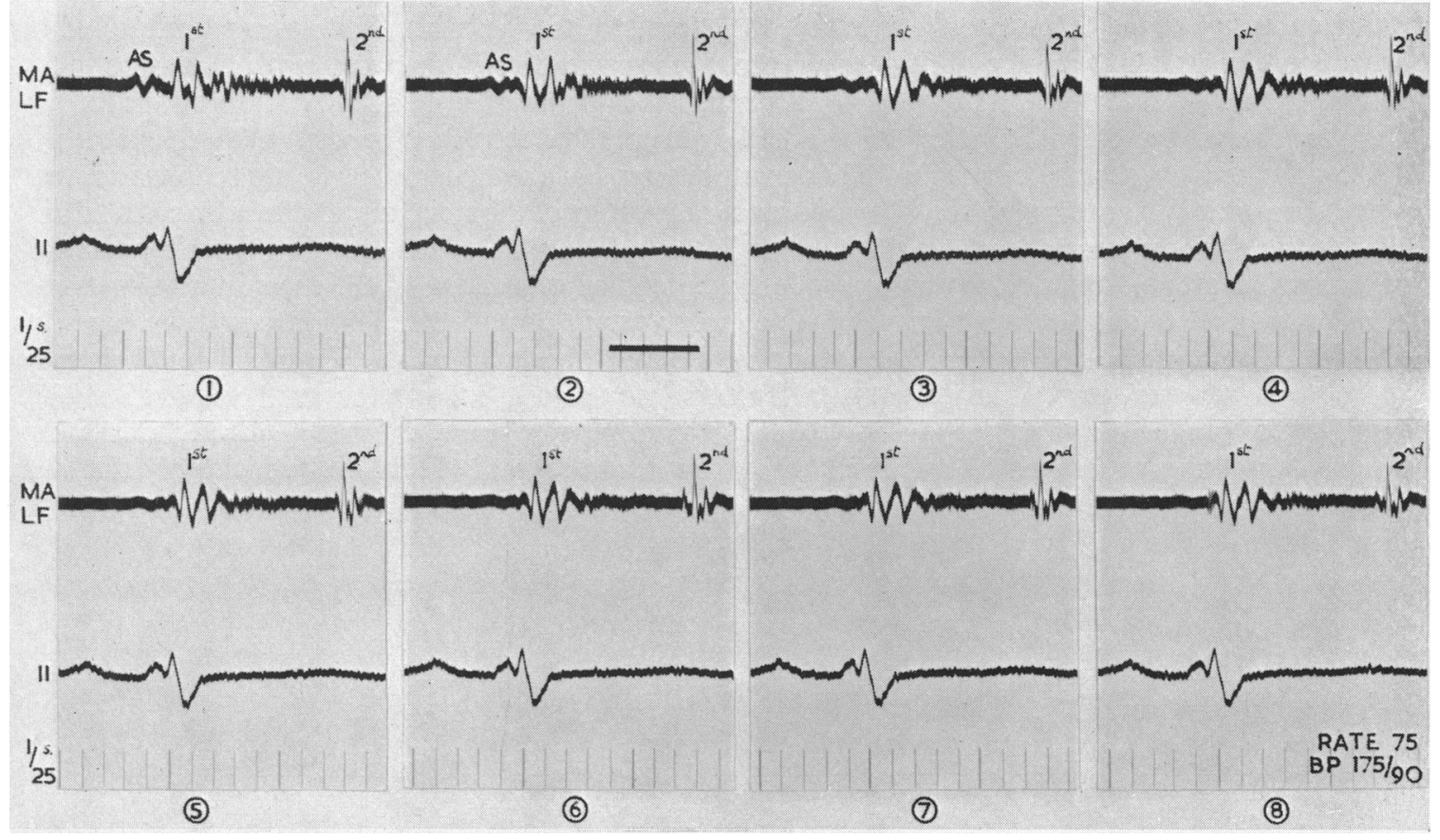

FIG. 2.-Ischæmic and hypertensive heart disease with atrial gallop. Effect of held expiration. Disappearance of atrial sound (AS) with held expiration during 8 heart beats (1 to 8). Recording of phonocardiogram started immediately at end of expiration. Electrocardiogram lead II. 1 st and $2 \mathrm{nd}=$ first and second heart sounds.

during held inspiration were less marked, but showed an initial increase followed by a decrease in amplitude.

The Effect of Posture. Sitting upright with the feet down was found to abolish the atrial sound in 9 out of 18 patients, all of whom had a clear atrial sound previously when lying down. On their lying down again, the sound reappeared (Fig. 3) and it persisted as long as they remained flat. Five of these patients had ischæmic heart disease and 4 had hypertension. Only minor changes in blood pressure accompanied the change from the sitting to the lying posture and these were not consistent, the pressure rising slightly in some and falling in others. The diastolic pressure never varied by more than $20 \mathrm{~mm}$. $\mathrm{Hg}$ : similarly the systolic pressure did not vary by more than $30 \mathrm{~mm}$. $\mathrm{Hg}$. Changes in heart rate were small, if any, the rate tending to increase by about five beats a minute on sitting up. There was no significant change in the P-R interval.

The Effect of Exercise was studied in 11 hypertensive patients, one of whom also had ischæmic heart disease. It was thought advisable to carry out only mild leg exercise in these patients, particularly when lying flat. The atrial sound became larger and earlier after exercise in one patient with ischæmic and hypertensive heart disease, a third heart sound appearing temporarily also (Fig. 4). In the remaining patients little change in the atrial sound occurred. The pulse rate rose in every patient with exercise but with only a small rise in blood pressure of up to $10 \mathrm{~mm} . \mathrm{Hg}$ diastolic.

The Effect of Venous Pooling was studied with the patients both in sitting and lying positions. All 9 patients retained their atrial sound, when they were sat up with the feet down before the venous cuffs were inflated on the legs. Five of them, however, lost the sound, after the cuffs had been inflated for about 10 minutes (Fig. 5); and of the remaining four, the sound became smaller in 3 and later in timing also in 1 (Fig. 6). 


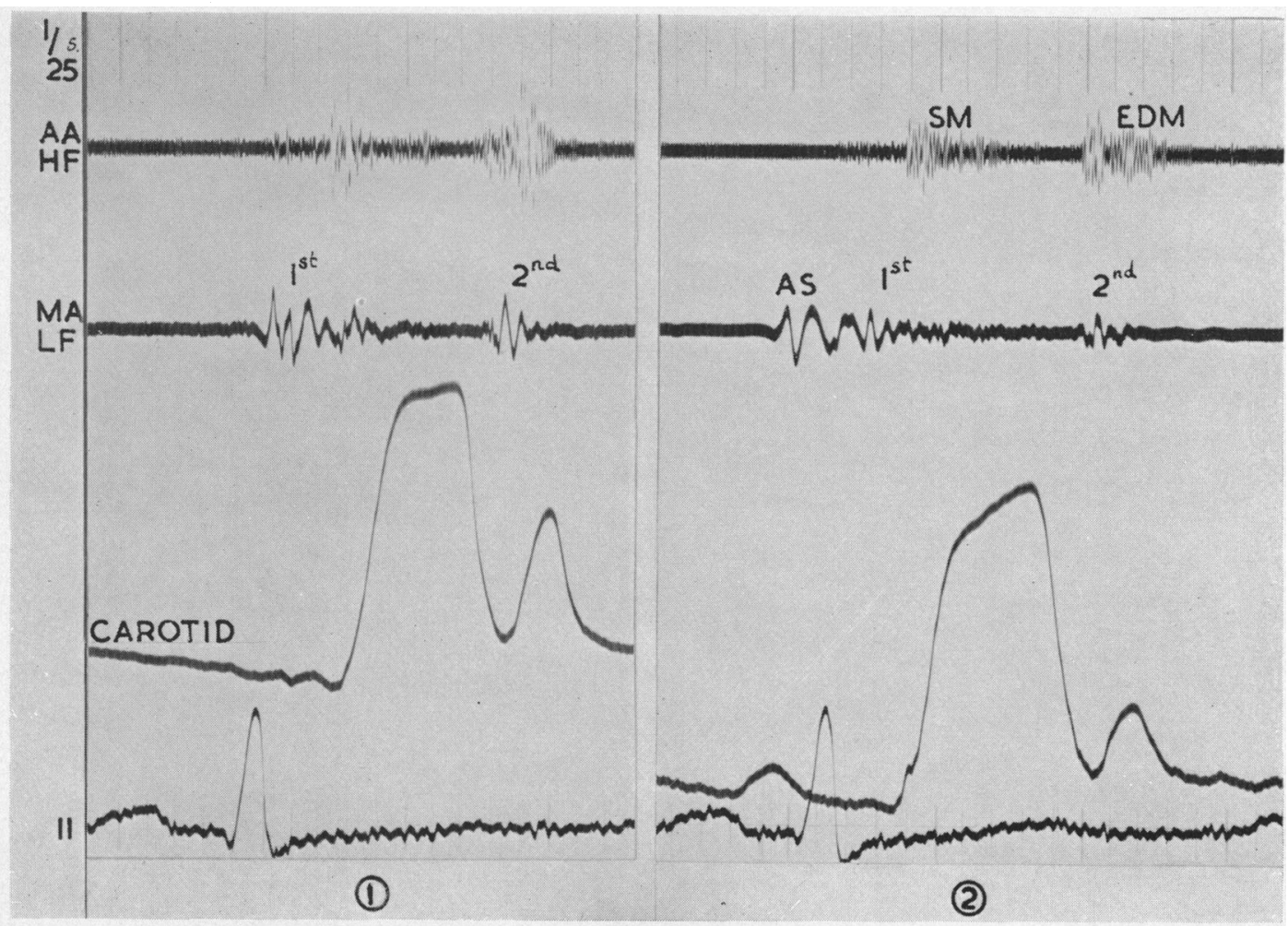

FIG. 3.-Hypertensive heart disease with atrial gallop. Effect of posture. Absence of atrial sound in sitting posture (1). Appearance of early atrial sound (AS), before $Q$ wave on lying flat (2). Blood pressure $=220 / 140 \mathrm{~mm}$. $\mathrm{Hg}$ in both positions and cycle length unchanged $(0.75 \mathrm{sec}$.). $\mathrm{SM}$ and EDM=systolic and early diastolic murmurs.

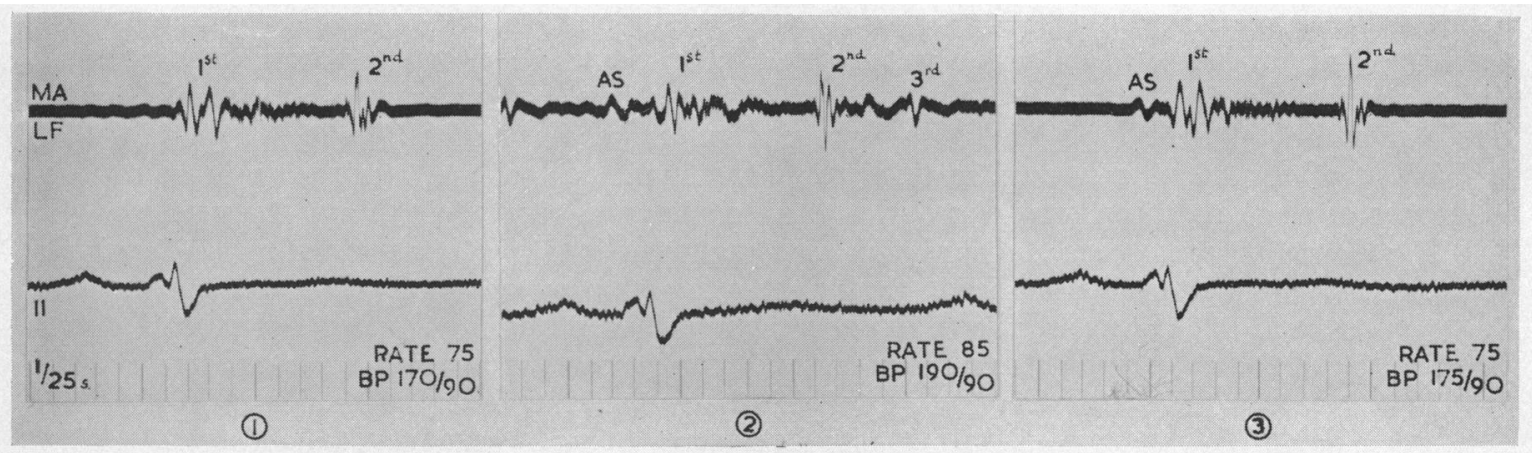

FIG. 4.-Ischæmic and hypertensive heart disease with atrial gallop. Effect of exercise. No clear third or atrial sound in resting phonocardiogram, lying flat (1). Transient quadruple rhythm with third (3rd) and atrial sound (AS), immediately after gentle leg exercise, lying flat (2). Disappearance of third sound one minute later, but persistence of atrial sound (3). Moderate increase of heart rate on exercise, with minor changes of blood pressure. 
The patient was then laid flat, with the cuffs on the legs still inflated, but this change of position did not have any marked effect on the atrial sound so long as venous pooling was continued. As soon as the cuffs were released, however, and the trapped blood in the legs returned to the circulation, striking changes in the atrial sound were seen in all patients. The sound now clearly returned, where previously abolished (Fig. 5): of the 4 patients, in whom cuffing had made the sound smaller or later in timing, uncuffing caused it to become larger and earlier again (Fig. 6).

Seven of the patients studied in this group had hypertension and 2 ischæmic heart disease. Changes in pulse and blood pressure during these manœuvres were slight, if any occurred.

The Effect of Intravenous Aminophylline was examined in 7 hypertensive patients. In all the atrial sound grew later and smaller in timing after the injection of aminophylline (Fig. 7) and in 3 it disappeared. It did not return to its former amplitude and timing during the period of observation, which varied between 20 and 30 minutes. Two patients showed a transient increase in the sound one minute after the injection, after which the sound grew later and smaller as in the other patients. With the exception of two patients there were no marked changes in blood pressure after the injection of aminophylline, but in all the heart rate increased.

Quadruple Rhythm. Two patients were noted to have a labile quadruple rhythm, in which at times the third and at times the atrial sound predominated, and they were therefore studied throughout 


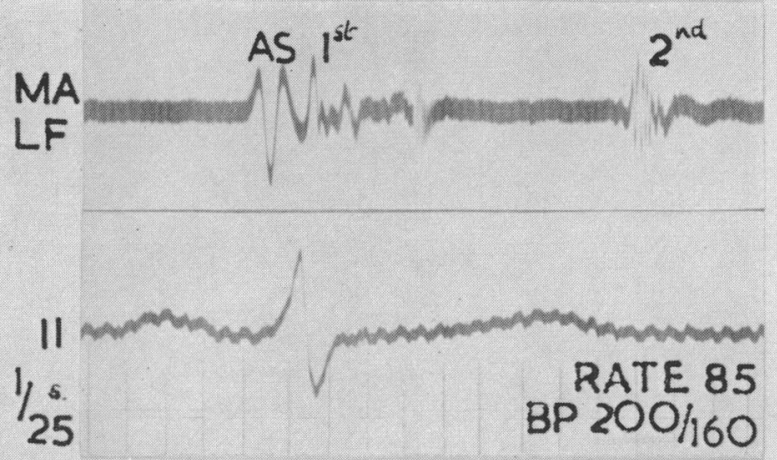

(1)
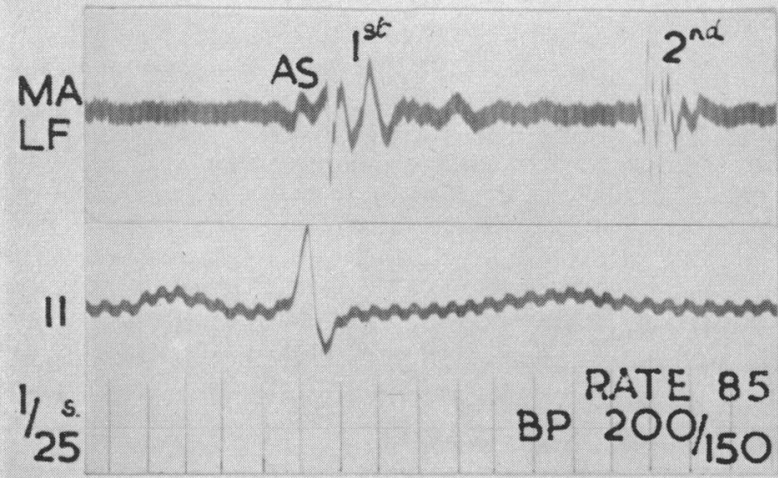

(3)

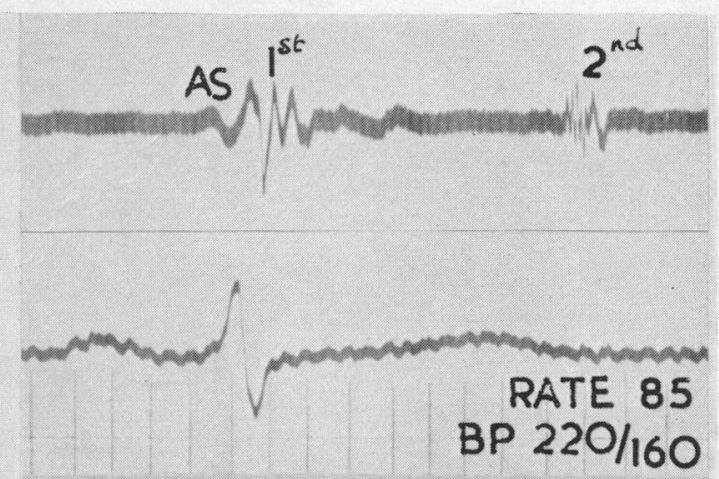

(2)
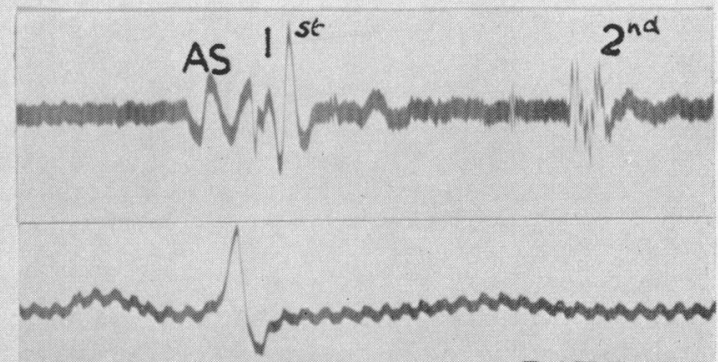

RATE 85 BP $210 / 140$

(4)

FIG. 6.-Hypertensive heart disease with atrial gallop. Effect of posture and venous pooling. Large atrial sound (AS), before the $R$ wave in sitting posture (1), becoming smaller and later (around $R$ wave) with venous pooling (2). Atrial sound unchanged on lying flat (3), but becoming larger and earlier again on release of cuffs

(4). Changes in blood pressure small and heart rate unaltered.

their month's stay in hospital on numerous occasions. One patient had hypertension, with grade III retinopathy, and was aged 37; the second was an older patient, aged 60 , who had hypertension and also recent cardiac infarction. The lability of their heart sounds suggested that they were on the verge of frank heart failure, for even minor stimuli, whether psychological such as a ward round, or physical such as rest, respiration, changes of posture, or venous pooling, were sufficient to change fundamentally the basic pattern of their gallop rhythm.

The Effect of Rest, Posture, and Venous Pooling. The extent of the manœuvres necessary to produce such changes in the heart sounds varied with the clinical state of the patient. At times prolonged rest on the couch in the phonocardiograph room was sufficient to produce marked improvement in the sounds. On other occasions changes in posture or venous pooling were required to produce the same degree of improvement.

Four successive stages in improvement were seen. First, there was gallop rhythm due to a third heart sound. This later gave way to quadruple rhythm with a clear atrial sound appearing de novo. This, in turn, was succeeded by gallop rhythm due to an atrial sound alone, until finally in the last stage both gallop sounds disappeared (Fig. 8). These stages in improvement could then be reversed by any manœuvre designed to increase again the venous return.

Accompanying these changes in the type of gallop rhythm, there were significant alterations in the amplitude and timing of both the third and the atrial sound throughout all four stages. In the 


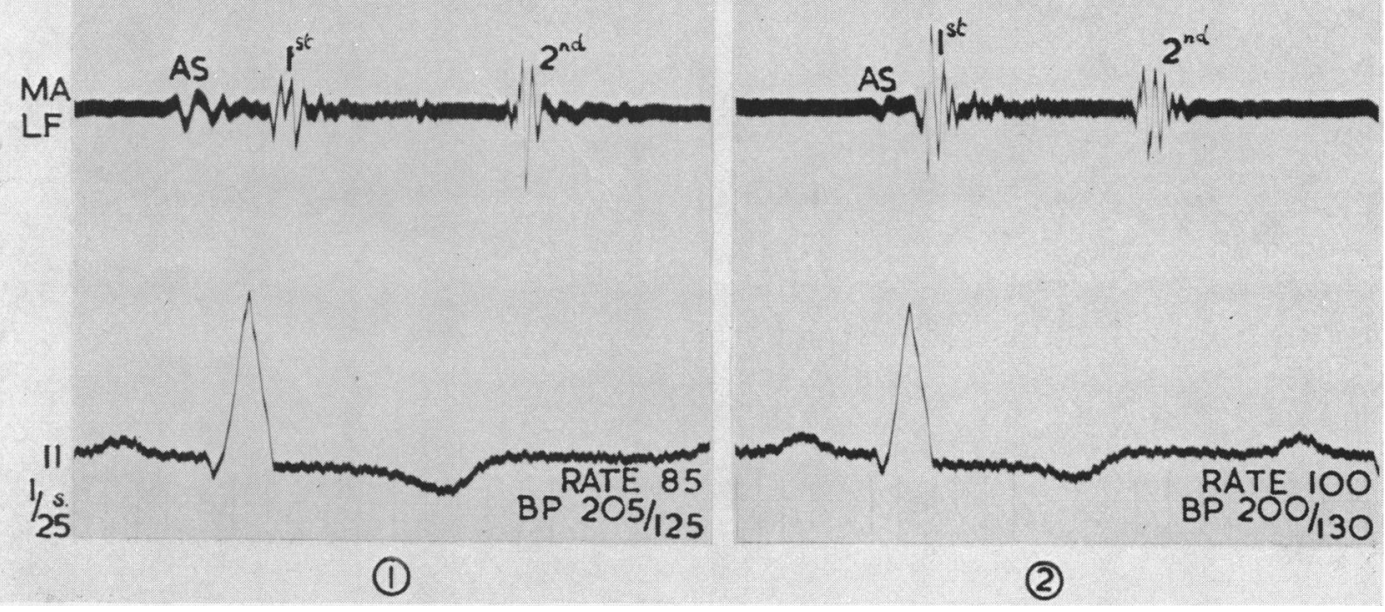

FIG. 7.-Hypertensive heart disease with gallop rhythm. Effect of intravenous aminophylline. Atrial sound (AS), large and early (before $Q$ wave in control phonocardiogram (1), becoming smaller and later (around Q wave) after intravenous injection of $0.5 \mathrm{~g}$. aminophylline (2). Heart rate increased from 85 to 100 a minute but little change in blood pressure.

first stage the lone third heart sound was large and early. In the second, when both an atrial and a third sound were present together, the third sound became smaller and later, while the atrial sound was early. In the third stage the lone atrial sound grew large and later in timing. In the fourth stage, the atrial sound gradually grew smaller, until it finally disappeared.

These changes in the type of gallop rhythm were observed with only small variations in the blood pressure, heart rate, or P-R interval, as in the previous studies on the atrial sound.

The Effect of Respiration. When the heart sounds had reached the second stage of improvement in this study, that is both a third and atrial sound being present together, the phases of normal quiet respiration had a most striking effect on the sound rhythm. On inspiration the third heart sound grew louder and the atrial sound disappeared. Toward the end of inspiration and at the beginning of expiration, the lone third heart sound reached enormous proportions and became earlier. Then, as expiration proceeded the third sound grew later and smaller, while simultaneously a large atrial sound returned (Fig. 9). These beat to beat variations of the gallop sounds accompanying phases of respiration seemed to reflect in microcosm the more lasting changes produced by rest, posture, or venous pooling.

\section{Discussion}

Our studies emphasize the liability of gallop sounds in hypertensive and ischæmic heart disease, which reflect not only the clinical state of the patient, but also physiological changes, such as respiration, posture, and exercise. Thus both the loudness and the timing of the atrial sound vary with posture and also with the phases of respiration. In addition, posture and respiration may actually alter the basic cadence of sounds, a third heart sound being replaced by an atrial sound. Caution is necessary, therefore, in interpreting relatively minor changes in these sounds in relation to clinical improvement or deterioration.

The Atrial Sound. Normal respiration alters phasically the venous return to the two sides of the heart, inspiration increasing the return to the right heart and diminishing the return to the left, while expiration has the opposite effect (Lauson et al., 1946). The changes in triple rhythm due to an atrial sound that we observed in patients with hypertensive and ischæmic heart disease during 


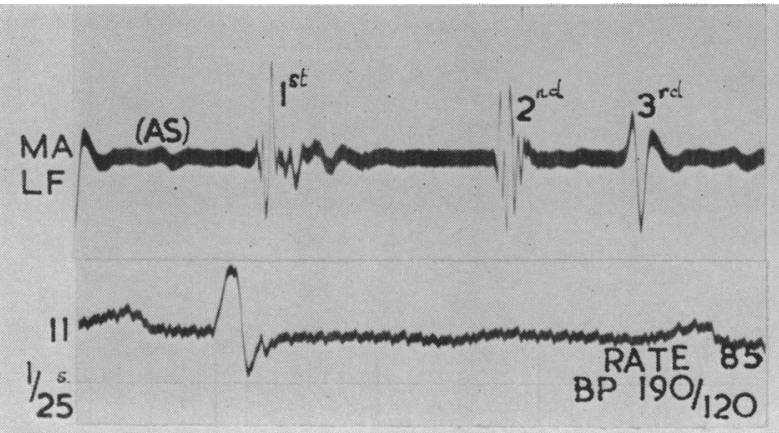

(1)
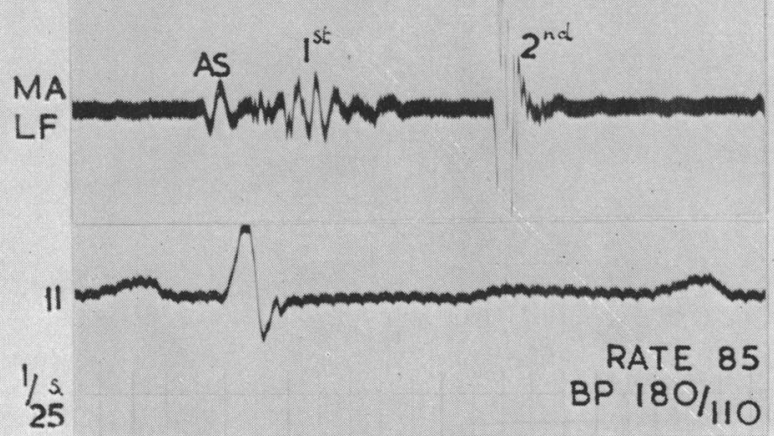

(3)

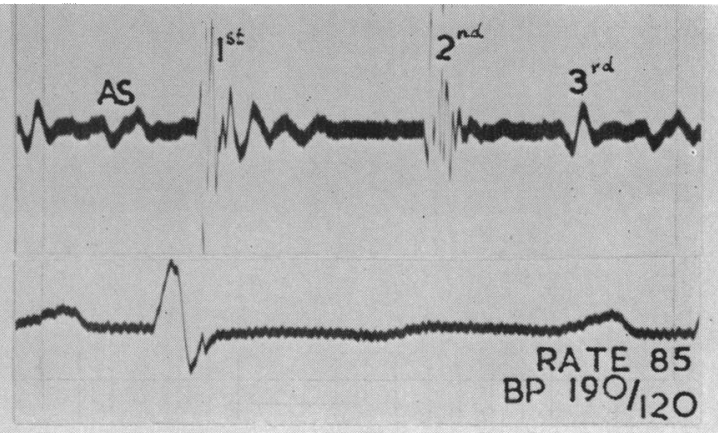

(2)
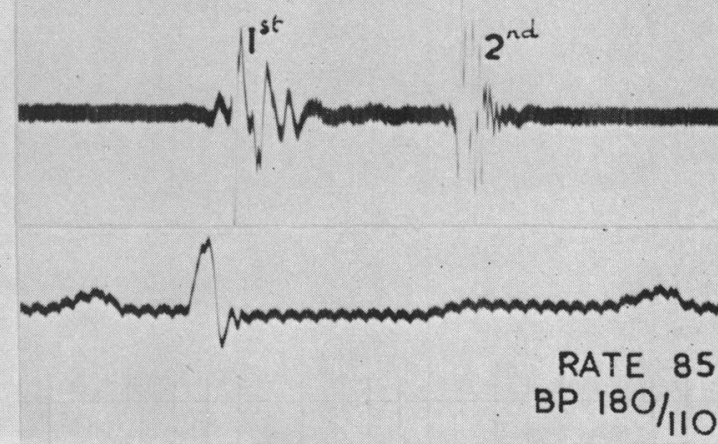

(4)

FIG. 8.-Hypertensive heart disease with quadruple rhythm. Effect of rest and venous pooling. Four stages in improvement illustrated. Stage 1: lying flat: large third sound (3rd) and rudimentary atrial sound. Stage 2: after 20 minutes rest, lying flat: quadruple rhythm with smaller and later third sound and larger and later atrial sound (AS). Stage 3: further prolonged rest, lying flat: lone atrial sound, later still in timing. Stage 4: lying flat with venous cuffs on thighs for 20 minutes: disappearance of both third and atrial sound. No significant change in heart rate or blood pressure throughout.

normal quiet respiration followed the pattern of increasing and decreasing venous return to the left heart, the sound being loudest at the beginning of expiration and smallest on mid-inspiration.

The marked effect of breath-holding in some patients is of importance, since phonocardiograms are often recorded in held expiration in order to free the base-line of interference from respiratory sounds. We found that by holding the breath in full expiration for only six heart beats it was possible to abolish completely a loud atrial sound. Breath-holding is essentially an unphysiological state and we feel that phonocardiograms for assessment of both atrial and third heart sounds should be recorded with continuous quiet respiration. Abolition of the atrial sound on held expiration is probably related to the fact that the stroke volume of both right and left ventricles falls on held expiration (Lauson et al., 1946).

Disappearance of the atrial sound in the sitting position in patients in whom the sound is easily heard in the recumbent position was noted by Kuo et al. (1951). It is probably related to the shift of blood into the lower part of the body and depletion of the central venous reservoir, with resultant fall in venous filling pressure and, in the normal circulation at any rate, a fall in cardiac output (McMichael and Sharpey-Schafer, 1944; Coe, 1954; Weissler et al., 1957). It seemed unlikely that simple changes in proximity of the heart to the chest wall could be responsible for changes in intensity of the sound, because of the opposite behaviour of the third and the atrial sound, when present together. Alteration of the position of the heart in relation to the chest wall would cause 


\section{SUCCESSIVE HEART SOUNDS THROUGHOUT ONE RESPIRATORY CYCLE}
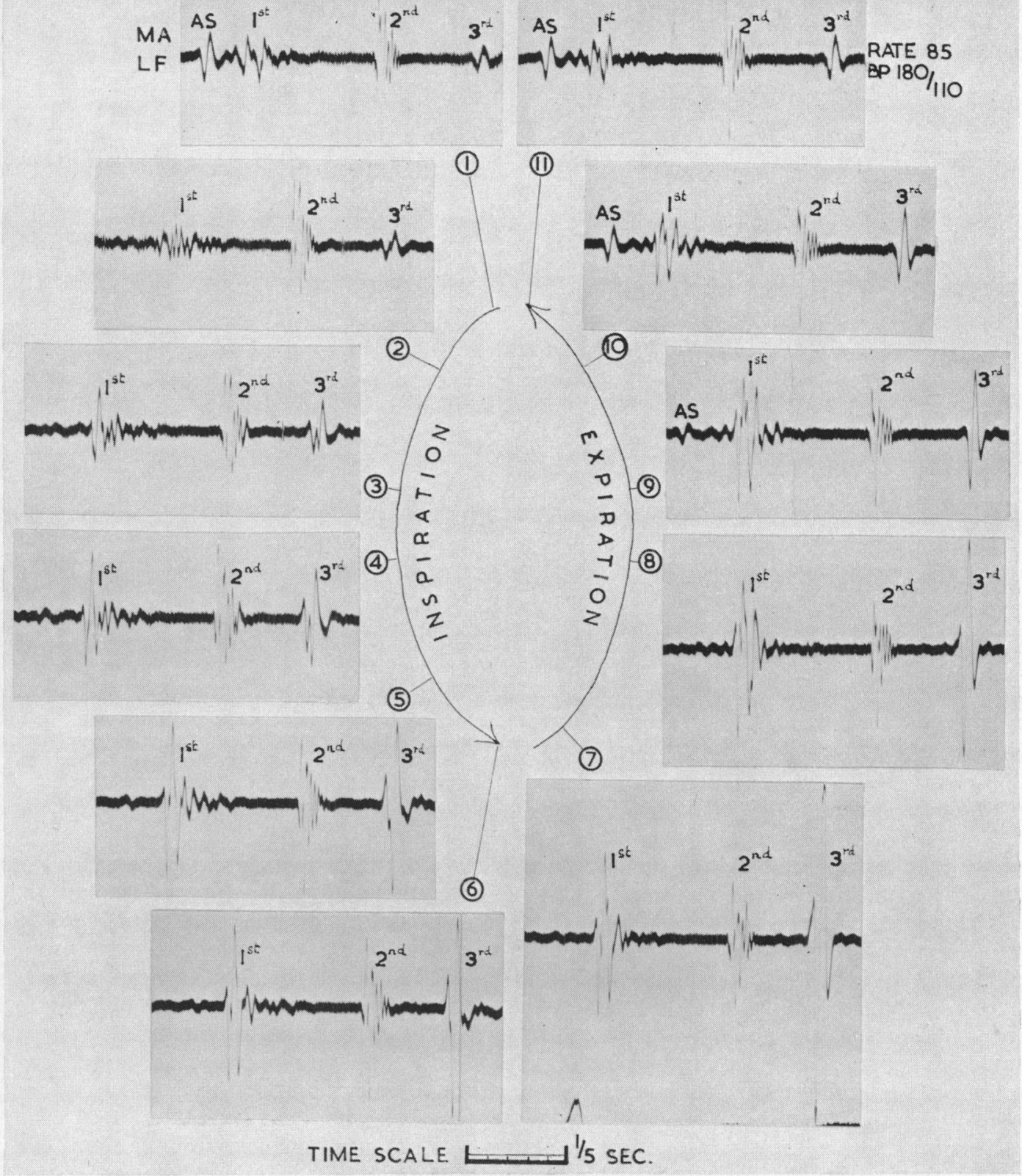

FIG. 9.- Hypertensive heart disease with quadruple rhythm. Effect of normal quiet respiration. Continuous phonocardiogram during respiration. Inspiration: Just kefore start of inspiration (1), quadruple rhythm. At beginning of inspiration (2), disappearance of atrial sound (AS), while third sound (3rd) larger and earlier. With continuing inspiration (3 to 6 ), third sound continues to grow larger and earlier. Expiration: At start of expiration (7), third sound largest and earliest. With continuing expiration (8 to 11), progressive decrease of third sound, becoming later again. In mid-expiration (9), reappearance of early atrial sound, which then grows larger and later ( 9 to 11$)$. 
both the third and the atrial sound to grow louder or softer simultaneously, whereas in fact one sound grew louder as the other grew softer.

The effect of gentle exercise was, perhaps, less than might have been expected. In one patient, however, a striking change resulted, an early loud atrial sound and a third sound appearing after exercise. An early loud atrial sound is an unfavourable clinical sign (Duchosal, 1932; KincaidSmith and Barlow, 1959) and so this change on gentle exercise together with the brief appearance of a third heart sound was an indication of the gravity of the patient's clinical state and lack of cardiac reserve.

The circulatory effects of pooling of blood by venous occlusive cuffs have been extensively studied (Warren and Stead, 1943; McMichael and Sharpey-Schafer, 1944; Fitzhugh et al., 1953). A fall in right atrial pressure with a concomitant decrease in cardiac output results in normal subjects. Leonard et al. (1958) studied the effect of venous pooling on the atrial gallop in hypertensive heart disease and found results similar to ours. They believed that the softening of the atrial sound with venous pooling was explained by atrial systole injecting less blood into the left ventricle, which is thus under less tension.

Aminophylline has been shown to lower right atrial pressure and to cause an immediate rise and later fall in cardiac output (Howarth et al., 1947). Werkö and Lagerlöf (1950) studied patients with hypertensive heart disease and showed a constant and significant fall in pulmonary capillary venous pressure, with usually a small rise in cardiac output, after $0.4 \mathrm{~g}$. aminophylline had been injected over a period of two minutes. The pulmonary capillary pressure did not rise to its former level until after about 30 minutes. The diminution of the atrial sound after aminophylline in our patients for half an hour or more accords well with Werkö's findings and suggests that the reduction in pulmonary capillary pressure may well have been the direct cause of the disappearance of the sound in our hypertensive and ischæmic patients. The immediate rise and later fall in cardiac output reported by Howarth et al. (1947) might explain the initial temporary increase in the atrial sound in a few of our patients.

Pathogenesis of Quadruple Rhythm. Possible factors responsible for accentuation of gallop sounds in disease include changes in myocardial tone, in ventricular and atrial volume, in venous filling pressure, and in stroke output of both ventricle and atrium. Disturbed myocardial tone from hypertrophy or ischæmia is probably one of the basic factors responsible for the sounds in hypertensive and ischæmic heart disease. It seems likely, however, that, in addition, acute variations in the atrial pressure from varying venous return may act on the diseased myocardium in such a way as to cause the sounds to change temporarily, without any basic change in the abnormal tone of the myocardium. This dual concept of the pathogenesis of the sounds would fit in with our observation that the patients would respond to manœuvres tending to diminish the venous return, such as rest, posture, or venous pooling, in the same general direction of improvement but to a different degree, depending on the general state of the circulation at the time of study.

The reciprocity of the third heart sound and the atrial sound, the one appearing when the other disappeared, seemed compatible with the concept of a critical venous filling pressure that is required to overcome the increased resistance to filling of the diseased and stiffened myocardium. According to this concept a lone loud third heart sound suggests that left atrial pressure in early diastole is sufficiently raised to overcome this increased resistance, so that filling is early, rapid, and prematurely complete in the diastolic rapid inflow period. Atrial systole, therefore, contributes little to ventricular filling, since this is virtually complete in early diastole, and hence there is no atrial sound. When the venous return is diminished by rest, posture, or venous cuffing, the atrial pressure in early diastole falls to more normal levels, but is now insufficient to overcome the increased resistance of the diseased left ventricle. The third heart sound, therefore, gradually disappears, but is replaced by an atrial sound. The appearance of an atrial sound suggests that atrial contraction now raises the atrial pressure above the critical level, so that the increased resistance of the left ventricle is overcome, not, as before, at the beginning, but at the end of diastole. In other words, active atrio-ventricular filling now predominates over passive filling (Potain, 1880; and Mounsey, 1959). 
Disappearance of both third and atrial sound, when the venous return is further reduced, may indicate that the degree of increased resistance of the ventricle to filling varies with the diastolic volume and stroke output, the basic disturbance being one of volume-elasticity cœfficient. Thus, with a smaller venous return the heart is able to fill in a more normal and even manner.

\section{SUMmaRY}

Alteration and disappearance of gallop sounds are important signs in assessing clinical improvement in hypertensive and ischæmic heart disease. Protodiastolic gallop, due to an accentuated third heart sound accompanying passive early diastolic ventricular filling, is known to be more ominous, while presystolic gallop, due to an accentuated atrial sound accompanying ventricular filling during atrial systole, is more benign. The timing of the atrial sound is also of importance, for when the sound is early and thus relatively widely separated from the first heart sound, the prognosis is graver.

We found that simple physiological manœuvres, such as respiration, posture, and exercise, profoundly modified the gallop sounds in 25 patients with hypertensive and ischæmic heart disease. The loudness and timing and indeed the presence of an atrial sound varied with the phases of respiration, with posture, and sometimes with exercise. Held expiration, which is the normal state in which a phonocardiograph is recorded, sometimes abolished the sound. Similarly sitting upright sometimes caused the sound to disappear. Venous cuffing and the intravenous injection of aminophylline also resulted in diminution or disappearance of the atrial sound.

In two patients with quadruple rhythm we were able to vary the nature of their gallop by the same physiological manœuvres, converting quadruple rhythm to a lone third heart sound, to an atrial sound, or abolishing both at will. Even normal quiet respiration was capable of producing these changes, thus emphasizing the importance of continuous respiration when recording the phonocardiogram.

Because of the large variations in the gallop sounds with these simple physiological manœuvres, we feel that caution is necessary in interpreting relatively minor changes in gallop rhythm in relation to the clinical progress of the patient.

We would like to thank Professor J. McMichael, F.R.S. for his interest and encouragement in the preparation of this paper, and also Miss Judith Willsher and Miss Jean Powell for technical assistance and Miss Rosemary Davies who typed the paper.

\section{REFERENCES}

Coe, W. S. (1954). Ann. intern. Med., 40, 41.

Duchosal, P. (1932). Amer. Heart J., 7, 613.

Evans, W. (1943). Brit. Heart J., 5, 205.

Fitzhugh, F. W., Jr., McWhorter, R. L., Jr., Estes, E. H., Jr., Warren, J. V., and Merrill, A. J. (1953). J. clin. Invest., 32, 1163.

Gibson, A. G. (1907). Lancet, 2, 1380.

Harrison, T. R. (1959). Johns Hopk. Hosp. Bull., 104, 290.

Harvey, W. P., and Corrado, M. A. (1956). Circulation, 14, 950.

Howarth, S., McMichael, J., and Sharpey-Schafer, E. P. (1947). Clin. Sci., 6, 125.

Kincaid-Smith, P., and Barlow, J. (1959). Brit. Heart J., 21, 470.

- - (1959). Brit. Heart J., 21, 479.

Kuo, P. T., Hildreth, E. A., and Kay, C. F. (1951). Ann. intern. Med., 35, 1306.

Lauson, H. D., Bloomfield, R. A., and Cournand, A. (1946). Amer. J. Med., 1, 315.

Leonard, J. J., Weissler, A. M., and Warren, J. V. (1958). Circulation, 17, 1007.

McKusick, V. A. (1958). Cardiovascular Sound. Williams and Wilkins, Baltimore.

McMichael, J., and Sharpey-Schafer, E. P. (1944). Brit. Heart J., 6, 33.

Mounsey, J. P. D. (1959). Brit. Heart J., 21, 457.

Potain, C. (1880). Gaz Hôp., Paris, 53, 529.

- (1900). Sem. médicale, 20, 175.

Thayer, W. S. (1908). Boston med. surg. J., 158, 713.

Warren, J. V., and Stead, E. A., Jr. (1943). Amer. J. med. Sci., 205, 501.

Weissler, A. M., Leonard, J. J., and Warren, J. V. (1957). J. clin. Invest., 36, 1656.

Weitzman, D. (1955). Brit. Heart J., 17, 70.

Werkö, L., and Lagerlöf, H. (1950). Scand. J. clin. lab. Invest., $2,181$. 